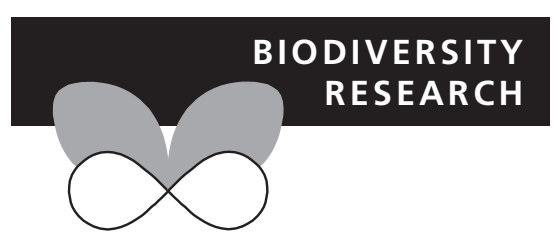

\section{Habitat availability for amphibians and extinction threat: a global analysis}

\author{
Gentile Francesco Ficetola ${ }^{1,2,3 *}$, Carlo Rondinini ${ }^{4}$, Anna Bonardi ${ }^{1}$, Daniele \\ Baisero $^{4}$ and Emilio Padoa-Schioppa ${ }^{1}$
}

\begin{abstract}
${ }^{1}$ Department of Earth and Environmental Sciences, University of Milano Bicocca, Piazza della Scienza 1, 20126 Milano, Italy, ${ }^{2}$ Laboratoire d'Ecologie Alpine (LECA), Université Grenoble Alpes, F-38000 Grenoble, France, ${ }^{3}$ CNRS, LECA, F-38000 Grenoble, France, ${ }^{4}$ Global Mammal Assessment Program, Department of Biology and Biotechnologies, Sapienza University of Rome, Viale dell'Università 32, I-00185 Roma, Italy
\end{abstract}

${ }^{*}$ Correspondence: Gentile Francesco Ficetola, Department of Earth and Environmental Sciences, University of Milano Bicocca, Piazza della Scienza 1, 20126 Milano, Italy. E-mail: francesco.ficetola@gmail.com

\begin{abstract}
Aim Habitat loss and degradation are the factors threatening the largest number of amphibian species. However, quantitative measures of habitat availability only exist for a small subset of them. We evaluated the relationships between habitat availability, extinction risk and drivers of threat for the world's amphibians. We developed deductive habitat suitability models to estimate the extent of suitable habitat and the proportion of suitable habitat (PSH) inside the geographic range of each species, covering species and areas for which little or no high-resolution distribution data are available.
\end{abstract}

\section{Location Global.}

Methods We used information on habitat preferences to develop habitat suitability models at 300-m resolution, by integrating range maps with land cover and elevation. Model performance was assessed by comparing model output with point localities where species were recorded. We then used habitat availability as a surrogate of area of occupancy. Using the IUCN criteria, we identified species having narrow area of occupancy, for which extinction risk is likely underestimated.

Results We developed models for 5363 amphibians. Validation success of models was high (94\%), being better for forest specialists and generalists than for open habitat specialists. Generalists had proportionally more habitat than forest or open habitat specialists. The PSH was lower for species having small geographical ranges, currently listed as threatened, and for which habitat loss is recognized as a threat. Differences in habitat availability among biogeographical realms were strong. We identified 61 forest species for which the extinction risk may be higher that currently assessed in the Red List, due to limited extent of suitable habitat.

Main conclusions Habitat models can accurately predict amphibian distribution at fine scale and allow describing biogeographical patterns of habitat availability. The strong relationship between amount of suitable habitat and extinction threat may help the conservation assessment in species for which limited information is currently available.

\section{Keywords}

Amphibian decline, deductive habitat suitability model, deforestation, extinction risk, IUCN RedList, land use, terrestrial habitat.

\section{INTRODUCTION}

Amphibians are one of the most imperilled animal taxa. Of the 6409 amphibian species for which conservation status has been assessed by the International Union for Nature Conservation (IUCN), 41\% are recognized as threatened by extinction, a figure much higher than the one observed in any other animal class (Stuart et al., 2004; Chanson et al., 2008; Hoffmann et al., 2010). The amphibian biodiversity crisis is not caused by one single agent: multiple threatening factors are recognized, including habitat loss and degradation, emerging pathogens, alien species, climate change, 
pollution, UV-B radiation and human-caused mortality (Stuart et al., 2004, 2008; Beebee \& Griffiths, 2005). Furthermore, threats may act in synergy, determining particularly severe consequences (Blaustein \& Kiesecker, 2002; Hof et al., 2012; Menéndez-Guerrero \& Graham, 2013). Even if the impact of some factors (e.g. pathogens, climate change or other emerging processes) is probably underestimated because of limited data, habitat-related processes remain the threatening factors affecting the largest number of amphibian species. According to the Global Amphibian Assessment, habitat loss and degradation are a major threat for $\sim 63 \%$ of all amphibian species (87\% of all threatened species) (Chanson et al., 2008).

Adequate knowledge on habitat availability is pivotal to develop conservation strategies, but this information is extremely limited for most of amphibians. Habitat suitability models can be successfully used to extract information on habitat availability and to guide conservation strategies (Rondinini et al., 2011b). These models can be particularly useful in poorly known areas and for analyses over broad scales, as they allow the development of spatially comprehensive predictions of suitable habitat and of potential distribution, on the basis of incomplete information (Rondinini et al., 2006). In recent years, habitat suitability models have become one of the most frequently used approaches in macroecology and biodiversity conservation, because of technical developments (e.g. remote sensing, statistical tools for the analysis of spatially explicit data, geographic information systems), and thanks to the growing availability of environmental layers and databases with information on species. Two broad classes of models exist as follows: inductive and deductive habitat suitability models (Corsi et al., 1999). Inductive models combine point localities (e.g. presence or presence/absence data) with environmental layers to derive statistical relationships. These relationships are then interpreted as representing suitability, can be used to produce suitability maps and to evaluate the potential impact of environmental changes (e.g. climate or land use changes). Inductive models are data intensive, as they require a large number of presence data to develop robust statistical relationships, and may be heavily biased if sampling is uneven (Kramer-Schadt et al., 2013; Ficetola et al., 2014a; LahozMonfort et al., 2014). For amphibians, high-resolution species presence localities are available for a limited number of species, and the quality (e.g. spatial resolution) of this information is particularly limited in the megadiverse, tropical regions (Ficetola et al., 2014b).

Deductive models are less frequently used, but constitute a valuable alternative. In this case, the knowledge of relationships between species and habitat is derived from expert knowledge and from the literature, to obtain ordinal scales of habitat suitability (Rondinini et al., 2006; Gaston \& Fuller, 2009). These models refine the resolution of geographical ranges by identifying the suitable and unsuitable habitat within them. Deductive models suffer some limitations: their output is limited to a qualitative evaluation of whether a given area is suitable for a given species (Rondinini et al.,
2006), and they may suffer bias because of subjectivity and incomplete information used for model development. Nevertheless, deductive models are a key approach for the identification of conservation priority over broad areas with incomplete biodiversity knowledge (da Fonseca et al., 2000; Maiorano et al., 2013; Almeida-Gomes et al., 2014) and have been demonstrated to predict accurately species distribution over wide geographical and taxonomic extents (Jenkins \& Giri, 2008; Rondinini et al., 2011a).

In this study, we performed the first analysis of the availability of habitat for amphibians at the global scale. We developed species-specific deductive habitat suitability models and validated a sub-sample of them. Subsequently, we evaluated the relationship between the proportion of suitable habitat (PSH), the extinction risk and the drivers of threat. Finally, we used the extent of suitable habitat (ESH, Beresford et al., 2011) to estimate the maximum potential area of occupancy of each species, which is a key parameter to assess species extinction risk using the IUCN Red List categories and criteria (IUCN, 2001). We identified species that may have a very limited amount of suitable habitat, and for which the current extinction risk may therefore be underestimated (Almeida-Gomes et al., 2014).

\section{METHODS}

\section{Development of models}

We used geographical ranges (vector polygons in ESRI shapefiles) and textual information on habitat preferences from the IUCN Red list to develop suitability models for amphibians, adapting the procedure described in Rondinini et al. (2011a). We produced models for 5363 species, that is $84 \%$ of amphibians evaluated by the IUCN (Appendix S1a), excluding species for which no habitat/range information was available, and for strictly aquatic/subterranean species for which we could not identify relationships with the habitat classification of the maps used to develop suitability models. The models were limited to within the IUCN range polygons of the species. Models considered two environmental parameters: land cover typology (including human influence and flooding occurrence) and elevation. Amphibians are capable of utilizing water bodies at a much finer temporal and spatial scale than available mapped sources (e.g. the use of small ponds or temporary puddles for reproduction); we therefore did not include water availability as a limiting factor. Information on elevation came from the shuttle radar topography mission digital elevation model, originally at approx. 90-m resolution at the equator (United States Geological Survey, 2006). Land cover data came from GlobCover v. 2.1 (IONIA, 2009), which is a global map with a 300-m resolution at the equator, classifying land cover in 63 classes based on the UN Land-cover Classification System (Di Gregorio \& Jansen, 2000). The GlobCover map was developed on the basis of images taken during 2005-2006 (Bicheron et al., 2008). All analyses were performed on an equal-area Mollweide projection in GRASS GIS (GRASS Development Team, 2008). 
Information on land cover preferences (preferred habitat types and tolerance to human impact) was extracted in two steps. First, we read the IUCN reports and identified the presence of each species in one or more broad habitat categories (forest, shrubland, grassland, bare and artificial). Each broad habitat category was associated with a suitability score (high, medium or low suitability) for each of the 63 GlobCover classes. This score was then integrated with information on known tolerance to human influence and (for strictly terrestrial species) flooding events, to obtain a more detailed suitability score: low tolerance to human presence or flooding would reduce the overall suitability if the GlobCover category indicates anthropic presence (e.g. degraded forest, mosaic of forest and pasture, crops, etc.) or floods (e.g. grasslands in permanently flooded lands). For a detailed table with all scoring combinations, see Appendix 2 in Rondinini et al. (2011a). Subsequently, if more detailed information on the habitat preference was available, we modified manually the suitability scores of specific land cover classes. As the information from IUCN sources only allowed to identify presence in very broad classes, and as suitability scores of each species were individually checked and fine-tuned, it was possible to apply the same scoring table developed in Rondinini et al. (2011a) without modifications.

The information on the minimum and maximum elevation within which each species lives, if available, was obtained from the IUCN Red List. Due to the uncertainty on the true elevation range of many species, the elevation range was extended $300 \mathrm{~m}$ either side. All areas outside each species' elevation limits were assigned low suitability. Pixels within the elevation limits retained the suitability value assigned to land cover. For the analyses of this study, the areas with medium and high suitability were summed to obtain the ESH, and the PSH was calculated dividing the $\mathrm{ESH}$ by the area of the species' geographic range.

Species were classified as (1) forest specialist; (2) species living in open habitats (e.g. shrubland and grassland); (3) habitat generalists (i.e. using both forest and open habitats). Shrubland and grassland species were merged because $0.7 \%$ only of analysed amphibians were associated exclusively to shrublands while, if generalists were excluded, $81 \%$ of shrubland amphibians were also associated to grasslands. Several studies have shown that, in amphibian communities, a gradient exist between forest specialists and species living in more open and sunny habitats (Skelly et al., 1999; Halverson et al., 2003). Strictly aquatic species that do not require terrestrial habitats were not included in the analysis.

\section{Model evaluation}

We used point locality data of species for independent evaluation of the habitat suitability models. These data were obtained from Ficetola et al. (2014b), which used the primary literature and the Global Biodiversity Information Facility (GBIF) to gather point presence localities of amphibians with the broadest geographic coverage. We considered only data collected after 1990, and for which the reported coordinate precision was $1 \mathrm{~km}^{2}$ or finer ('High quality data' in Ficetola et al., 2014b). Furthermore, we considered only species for which at least five separate presence points (i.e. more than $1 \mathrm{~km}$ apart) within the species' range were available (Rondinini et al., 2011a). Overall, we obtained 115 species with point locality data for model validation (see Results for information on their geographic coverage). Models were validated following Rondinini et al. (2011a); to match the resolution of validation points, validation was performed at the $1 \mathrm{~km}^{2}$ spatial scale. For each of the 115 species, we calculated validation success as the proportion of correctly predicted occurrences, that is the proportion of occurrence points falling within $1 \mathrm{~km}$ from cell having high and/or medium suitability habitat (i.e. point prevalence). We then compared this value with the model prevalence, which was calculated as the proportion of all cells within $1 \mathrm{~km}$ from high or medium suitability cells (i.e. the proportion of species range predicted as suitable). If the point prevalence is higher than model prevalence, the model performs better than the geographical range at predicting true species presences (Rondinini et al., 2011a). Model prevalence does not correspond to the percentage of habitat available for each species, because model prevalence also includes the unsuitable cells within $1 \mathrm{~km}$ from the suitable ones.

\section{Analysis of habitat availability}

We used ANOVA to evaluate whether validation success was significantly different among continents or for species living in different habitats. Subsequently, we attempted to identify factors correlated to the PSH. The coordinates of the centroid of the range of each species were used to model spatial correlation, as the residuals of preliminary general linear models were affected by spatial autocorrelation (model relating \% habitat availability to zoogeographic realm and habitat typology: Moran's $I=0.06, P<0.001$; model relating \% habitat availability to IUCN category and range size: $I=0.08, P<0.001$; model relating \% habitat availability to realm and threat: $I=0.06, P<0.001)$. Spatial autocorrelation may influence the results of statistical models, by biasing the results of significance tests and altering regression coefficients. We therefore used generalized least squares (GLS) to build our models. GLS allows the incorporation of spatial structure into the error of the model and is considered among the techniques with the best performance for the analysis of spatial data (Dormann et al., 2007; Beale et al., 2010). We built preliminary models using spherical, Gaussian and Exponential spatial correlation structure. The Exponential spatial correlation was then selected, as models with this error structure showed the lowest Akaike's information criterion scores. Nevertheless, results are identical with the spherical and Gaussian models.

First, we evaluated whether the PSH (i.e. the range proportion with suitability scores indicating medium or high suitability) was different for species with different habitat 
typologies (forest specialist, open specialist, generalist) or across biomes. For this purpose, we considered the 11 biogeographical realms identified by recent quantitative analyses (Holt et al., 2013). Second, we evaluated whether the proportion of suitable habitat is different among species with different threat levels, according to the IUCN Red List (IUCN, 2013). As IUCN category is also strongly related to range size (Cooper et al., 2008), we also included range size in this model. Third, we evaluated whether the PSH was lower for species threatened by habitat loss. Before analysis, the PSH was arcsine-squareroot-transformed and species range was log transformed to reduce skewness and improve homoscedasticity. Partial regression plots were used to represent the relationship between the dependent and each explanatory variable, while keeping the other variables constant (Maindonald \& Braun, 2010; Breheney \& Burchett, 2013). Analyses were performed in R (R Development Core Team, 2013) using the NLME package; partial regression plots were developed using the VISREG package (Breheney \& Burchett, 2013).

\section{Identification of potentially threatened species}

We used the ESH, obtained through the habitat models, to identify species for which the extinction risk is likely underestimated. The ESH was used as a maximum possible estimate of area of occupancy (AOO) (Almeida-Gomes et al., 2014). Indeed, species rarely occupy all suitable habitats within their range, and therefore, the AOO is likely to be smaller than the ESH. Two IUCN criteria evaluate threat status on the basis of AOO: criterion B2 and criterion D2 (IUCN, 2001). A species is classified as vulnerable according to criterion D2 if the AOO is $<20 \mathrm{~km}^{2}$ and if potential future threats for the species exist (i.e. human-modified habitat within the species range or possible decline). Criterion B2 requires ongoing decline of habitat or populations and severe fragmentation of habitat/species present in a few localities only. We thus assumed that a species might qualify for criterion. B2 if: $\mathrm{AOO}<10 \mathrm{~km}^{2}$ (potential status: critically endangered, $\mathrm{CR}$ ), $\mathrm{AOO}<500 \mathrm{~km}^{2}$ (potential status: endangered, $\mathrm{EN}$ ), $\mathrm{AOO}<2000 \mathrm{~km}^{2}$ (potential status: vulnerable, VU), and (a) the IUCN Red List currently reports ongoing decline and severely fragmented range/1-10 locations (depending on the IUCN categories, see IUCN, 2001) or (b) $>75 \%$ of the range is already occupied by unsuitable habitat and dominated by human-modified habitats. Visual examination of habitat maps confirmed severe habitat fragmentation for all the species meeting condition (b). This alternative criterion was used if no data on the decline was reported in the Red List, and assumes that, if a species already lost $>75 \%$ of its habitat, decline is likely. Criterion B2 is not frequently used in the present version of the amphibian Red List, due to the complexity of obtaining estimates of AOO (Stuart et al., 2008). We excluded from this analysis species for which current distribution maps are just circles around one or a few localities. This revaluation was performed on forest amphibians only, as models showed the highest performance with these habitat specialists (see Results).

\section{RESULTS}

\section{Validation of models}

Point occurrences were available for species from all continents (Europe: $N=15$ species, North/Central American: $N=43$; South America: $N=20$; Africa: $N=9$; Asia: $N=17$; Oceania: $N=11$ ), and the average $( \pm \mathrm{SD}$ ) number of points available for model validation was $80 \pm 391$ per species. For species with validation points, the proportion of species range predicted as suitable was $0.79 \pm 0.21$. The average validation success, weighted for the number of validation points, was $0.94 \pm 0.79$. Validation success was significantly higher for forest specialists (weighted average $=0.94$ ) and habitat generalists (0.95) compared with species living in open habitats (0.84), and differences were statistically significant (ANOVA with weighted sum of squares: $F_{2,112}=9.74, P<0.001$ ), while there were no significant differences among continents $\left(F_{2,112}=1.44, P=0.22\right)$. There was no relationship between number of records and validation success (Spearman's correlation: $r_{\mathrm{S}}=0.08, N=115, P=0.93$ ). Models predicted species occurrences better than random points in $79 \%$ of cases (91 of 115 species).

\section{Variation in habitat suitability}

The average proportion of suitable habitat $( \pm$ SD) was $0.55 \pm 0.26$ for forest species, $0.42 \pm 0.27$ for open habitat species and $0.61 \pm 0.27$ for habitat generalists. Differences among habitat typologies were strongly significant (GLS: $\left.F_{2,5330}=116.3, \quad P<0.0001\right)$. Differences were also strong among zoogeographic realms $\left(F_{10,5330}=24.1, P<0.0001\right)$, with suitability values generally low for the Saharo-Arabian and Oriental realms, particularly for habitat specialists, and generally higher for the Australian and the Nearctic realms (Fig. 1). Furthermore, we detected significant interaction between habitat typology and realm $\left(F_{20}, \quad{ }_{5330}=4.4\right.$, $P<0.0001$ ), because the availability of certain habitat typologies strongly varied among realms For instance, as expected the proportion of habitat was very low for the few forest species of the Saharo-Arabian realm (Fig. 1).

The percentage of suitable habitat strongly varied among amphibians assigned to different IUCN categories (GLS: $F_{5,5356}=19.6, P<0.0001$ ), with species belonging to high threat categories clearly having less available habitat (Fig. 2a). Furthermore, when taking into account threat status, suitability was higher for species with large ranges $\left(F_{1,5356}=123.3, P<0.0001\right.$; Fig. $\left.2 b\right)$.

For $64.4 \%$ of species analysed, habitat loss is listed as a current threat. Habitat availability was generally lower for these species $(0.54 \pm 0.25)$ compared with species for which habitat loss was not considered to constitute a current threat 


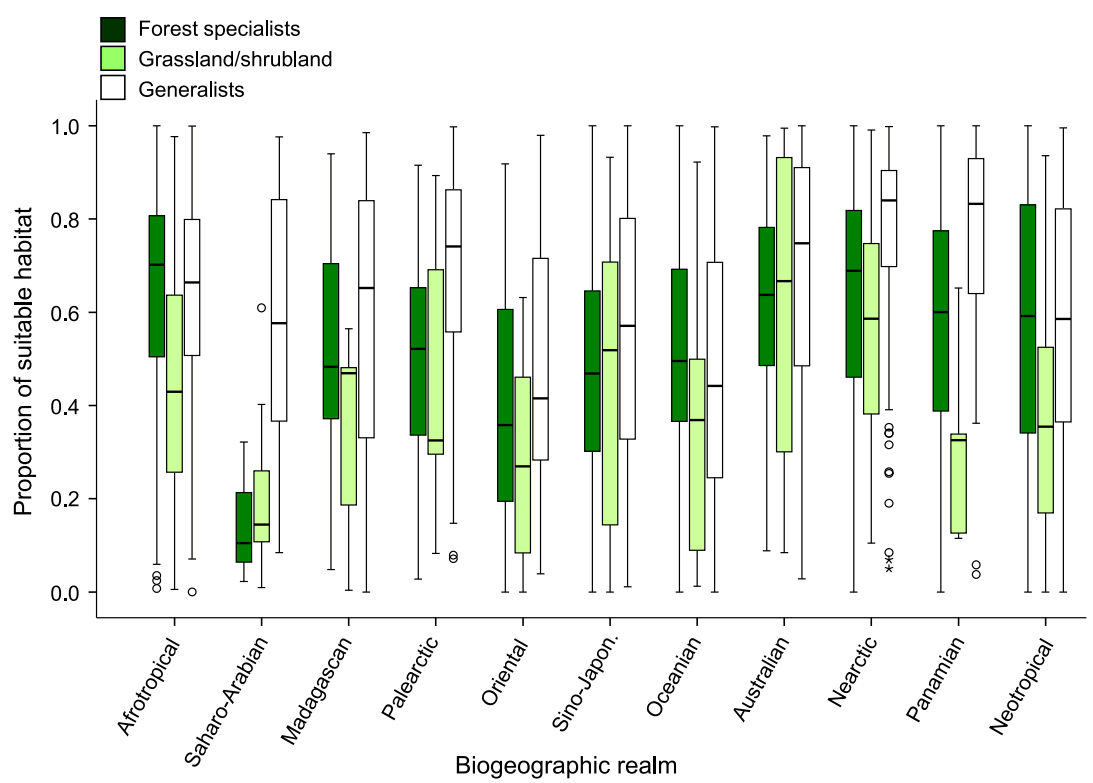

Figure 1 Proportion of suitable habitat for amphibians with different habitat specialization [forest specialists, specialists of open habitats (grassland/ shrubland), generalists] taking into account differences among zoogeographic realms (Holt et al., 2013).
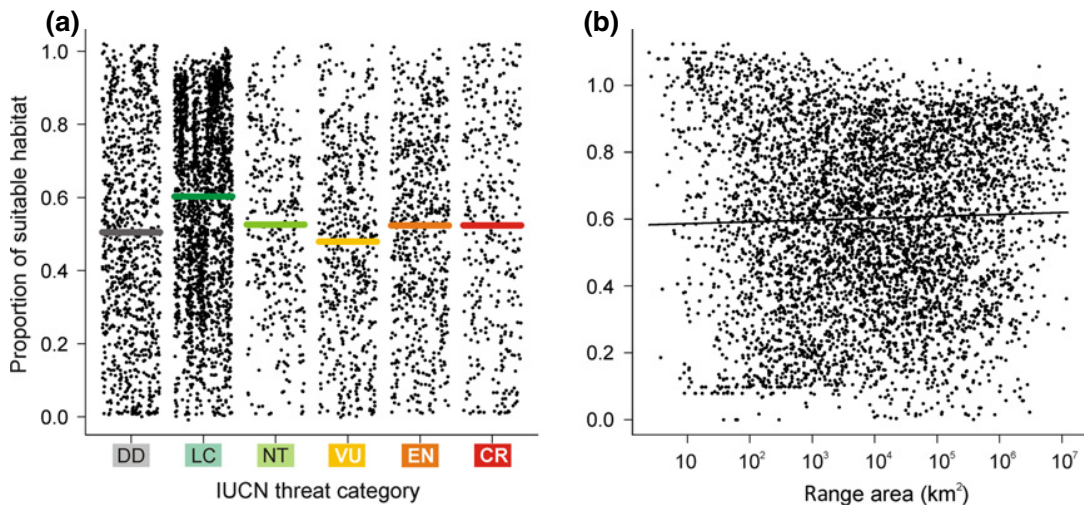

Figure 2 Partial regression plots showing the relationship between proportion of suitable habitat, IUCN category and range size for amphibians. In a), we show the average proportion of suitable habitat for each IUCN category (DD: data deficient; LC: least concern; NT: near threatened; VU: vulnerable; EN: endangered; CR: critically endangered) after taking into account variation in range size. Dots represent the partial residuals of all the species belonging to the same category; the horizontal distribution of points in each IUCN category only serves to render the density of points easier to read. In b), we show the relationship between range size and proportion of suitable habitat.

$(0.57 \pm 0.29)$. The difference between these two groups was limited but statistically significant (GLS taking into account differences among biogeographical realms: $F_{1,5341}=30.0$, $P<0.0001)$. This pattern was consistent across most realms (Fig. 3). Nevertheless, differences among realms were strong $\left(F_{10,5341}=23.1, P<0.0001\right)$. The interaction between threat typology and realm was statistically significant $\left(F_{10,5341}=3.4\right.$, $P=0.0002$ ), and in two realms, we detected the opposite pattern: species threatened by habitat loss did not show lower suitability (Saharo-Arabian and Oriental realms; Fig. 3).

\section{Species suffering underestimation of extinction risk}

We identified 61 forest species for which current extinction risk may be underestimated (Appendix S1c). Five data deficient (DD) species potentially have AOO $<20 \mathrm{~km}^{2}$ and might be considered VU according to Criterion D2. Furthermore, due to the very small amount of habitat and ongoing declines/heavy habitat modifications, two DD species might be considered CR; 44 more species might be EN and ten more species might be VU (Appendix S1b). Overall, species possibly in need of re-evaluation were from Central America (3 species), South America (31), Africa (9) and Asia (17) (Appendix S1b). In the present version of the Red List, no criteria are applicable for $63.9 \%$ of these species, while criteria $\mathrm{B} 1$ (EOO) and $\mathrm{B} 2$ (AOO) are used for $29.5 \%$ and $6.6 \%$ of these species, respectively.

\section{DISCUSSION}

We present the first global evaluation of habitat availability for amphibians. We show that deductive models can 
Figure 3 Proportion of suitable habitat for amphibians for which habitat loss is listed/not listed (open vs. filled) as a current threat in the IUCN Red List, when taking into account differences among zoogeographic realms.

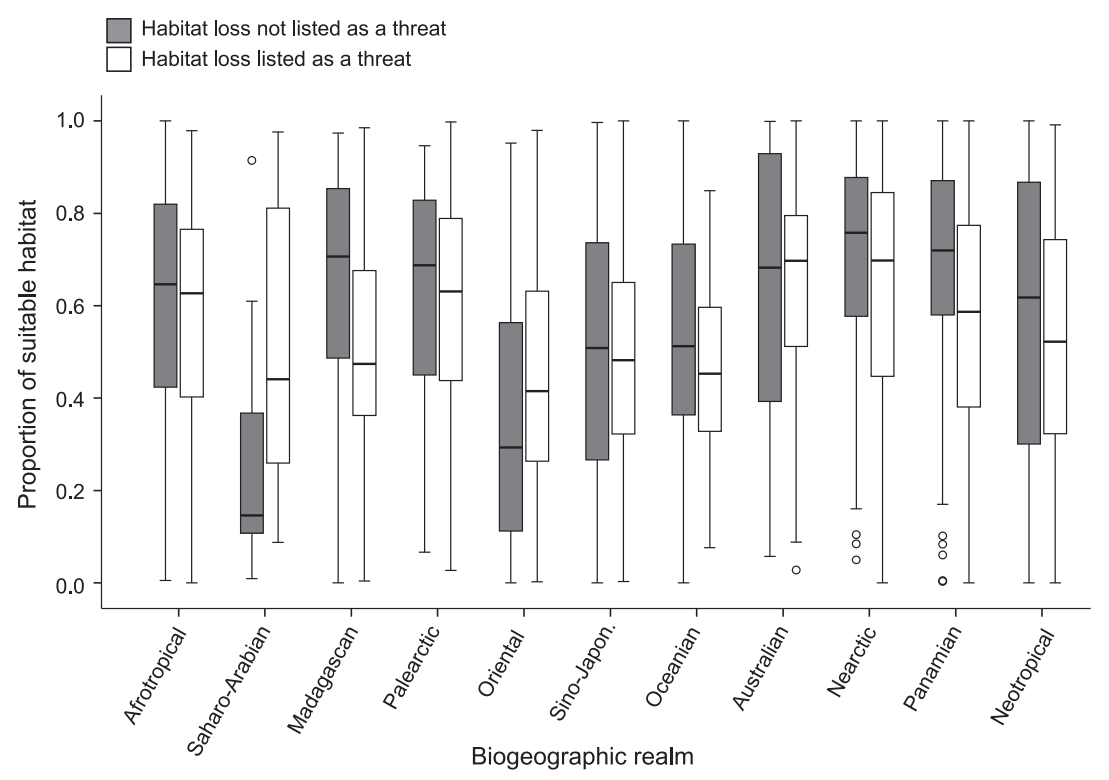

accurately predict species distribution at fine scale, we describe biogeographical patterns of habitat availability, and we show how our estimates of habitat availability can help to improve the present evaluation of amphibian extinction risk.

\section{Variation of habitat availability}

The IUCN Red List is mostly based on expert opinion, and its output has been sometimes criticized because species status is assessed even in the absence of quantitative data (Clements et al., 2011). In our quantitative analysis, the proportion of available habitat was consistently lower for threatened species, and for species for which habitat loss is considered a threat (Figs $2 \& 3$ ), confirming the IUCN evaluation. Among the species threatened with extinction according to the Red List, those classified as vulnerable (VU) were the ones with lowest proportion of suitable habitat, when taking into account range size (Fig. 2a). A similar pattern was detected for mammals: critically endangered mammals have a higher proportion of suitable habitat than the vulnerable or endangered ones (Rondinini et al., 2011a). This is not necessarily surprising, because amphibians suffering the highest threat levels (EN and CR) are often threatened by multiple stressors (e.g. emerging infectious diseases), often have very small distribution ranges, and sometimes are taxa showing enigmatic declines even in apparently pristine habitats (Lips et al., 2004; Menéndez-Guerrero \& Graham, 2013). Therefore, these species may be classified according to criteria other than area of occupancy, such as population reduction and small population size. This particular trend is also seen in other taxa: in mammals, for example, only 28 of 211 critically endangered species are classified with criterion B2 (IUCN, 2014).

The biogeographical variation of habitat availability was strong. The Saharo-Arabian and Oriental realms were the areas with less proportion of available habitat for amphibians
(Figs 1 \& 3). The result for the Saharo-Arabian realm was expected, as this region is dominated by deserts that are clearly unsuitable for most amphibians. Incidentally, this was the realm with the least species in our dataset (26). Conversely, the situation of the Oriental realm is particularly alarming. This is among the regions with the highest amphibian richness, but also in which amphibian biodiversity is heavily underestimated (Bain et al., 2008). Unfortunately, the Oriental realm is also the tropical area suffering the strongest deforestation, and the rate of habitat conversion is growing at an unprecedented rate there (Wright \& Muller-Landau, 2006; Hansen et al., 2013), with the risk of multiple amphibian extinctions because of habitat loss, even before species description. The integration of habitat suitability models with information on land use changes, for example, obtained from satellite images taken in different periods, may be an important tool for the identification of species most threatened by ongoing habitat loss. Differences among biogeographical realms may be partly due also to the different ability of the coarse habitat types used in the study to capture important habitats for amphibians. In different parts of the world, the same macrocategories may perform differently as predictor of suitable habitats. Individual species could depend on small-scaled features that can be found in one or more habitat(s) in different regions, this contributing to variation of habitat availability.

There are several explanations for the lower model performance of open habitat species. First, in land cover maps the accuracy of classification of open habitats may be lower than the one of forest or human-dominated habitats (Bicheron et al., 2008). Furthermore, open habitat amphibians often require small landscape elements that are difficult to capture in broad scale habitat maps (Joly et al., 2001; Mendenhall et al., 2011). The higher performance of models for forest/generalist species and the difficulties of capturing the requirements of open habitat species through remote sensing might 
explain why the latter tended to show less available habitat (Fig. 1). Furthermore, open habitats are less widespread than forest ones in ecoregions with high amphibian diversity (Olson et al., 2001) and may suffer particularly strong impacts. Temperate grasslands, savannahs and shrublands are among the habitats suffering the highest human pressure, but are also among the ones with the lowest level of protection at the global scale (e.g. $4.6 \%$ of temperate grasslands and shrublands protected, compared to $9.8 \%$ of temperate broadleaf forests; see Hoekstra et al., 2005). Therefore, amphibians specializing in these environments may have less protected areas limiting habitat loss and degradation.

\section{Methodological limitations}

Due to the detail of available underlying data, our analysis suffers multiple sources of uncertainty. The IUCN maps and assessments are the sole and most complete source of information for amphibians at the global scale (Stuart et al., 2004; Chanson et al., 2008), nevertheless such data have limitations. For instance, these range maps are in some cases an imperfect representation of the true species distribution (Ficetola et al., 2014b). Furthermore, the biology of many species is only partially known and in multiple cases information is based on anecdotal observations. Therefore, habitat preferences and elevation ranges suffer some degree of uncertainty. Nevertheless, the validation of models for a subset of species suggests that they generally have good performance, particularly for forest specialists and generalists.

Our models focused on terrestrial habitats, but many amphibian species require water for reproduction. The necessary complementation between suitable terrestrial habitats where adults live and suitable water bodies for reproduction means that true habitat requirements of many amphibians are more complex than depicted here (Pope et al., 2000; Becker et al., 2007). For several species, our models somehow overestimate suitability: we could not take into account the presence of suitable breeding habitats, and a potentially suitable terrestrial habitat might remain unoccupied if it is far from breeding wetlands, or in the presence of barriers. Unfortunately, remote sensing can measure the availability of small landscape elements such as ponds only over reduced geographic extents (Curado et al., 2011; Mendenhall et al., 2011), with no global data available. Nevertheless, our models lend themselves to be refined at local scale, in areas where such data are available (Almeida-Gomes et al., 2014). Finally, lack of sufficiently detailed data from remote sensing hampered the application of our models to strictly aquatic and fossorial species. Actually, fossorial species are often among the less known amphibians, and many of them are currently listed as data deficient. Fine scale studies are particularly important to understand the habitat requirements of these species (Ficetola et al., 2012).

\section{Habitat quantification to improve threat assessment}

Habitat models are a powerful tool to refine ranges and estimate extent of suitable habitat, which can be used as a maximum possible estimate of species' area of occupancy (sensu Gaston, 1991). The actual area of occupancy is expected to be smaller than the extent of suitable habitat for most species, as they rarely occupy all suitable habitats within their range due to other limiting factors (biogeographical, historical and ecological factor not accounted for in our models, including predators and competitors). Almeida-Gomes et al. (2014) recently showed that the extent of suitable habitat can be used to flag species that, despite being currently classified as data deficient (DD), may be threatened with extinction due to the very limited habitat available to them. Until now, quantitative measures of area of occupancy and of habitat availability only rarely existed, and therefore, criterion B2 was not often used in the amphibian Red Lists (Stuart et al., 2008). Our global habitat maps allowed us to identify a set of forest species for which the extinction risk may be underestimated because of limited habitat availability, high fragmentation and ongoing habitat deterioration. The majority of these 'underestimated' species are currently listed as least concern or data deficient, but the limited habitat availability may provide sufficient information for the inclusion in a threat category (Appendix S1c), while about one-third of these species are already considered vulnerable, but their small extent of suitable habitat suggests a higher threat category. Our results were not identical to the ones of Almeida-Gomes et al. (2014), as the latter identified two Atlantic forest frogs (Hylodes charadranaetes and $H$. pipilans) as likely endangered because of an AOO $<200 \mathrm{~km}^{2}$. We did not develop models for $H$. pipilans because very limited habitat information was available on this species on the Red List (Angulo, 2008), while the extent of suitable habitat for $H$. charadranaetes with our approach was broader (about $630 \mathrm{~km}^{2}$, vs. $182 \mathrm{~km}^{2}$ in Almeida-Gomes et al., 2014). The smaller AOO of Almeida-Gomes et al. (2014) is related to the more accurate information on habitat requirements they used for model development (width of suitable riparian buffer zones), that was not available for our global set of amphibian species. Despite the imperfect information, we believe that our models are a feasible and reliable strategy to obtain a coarse but robust assessment of potential habitat within range for species for which some basic information is available, thereby helping to identify species for which extinction risk is underestimated (see also Howard \& Bickford, 2014). These assessments may be then refined at local scale with information on populations and breeding habitats, to provide information for conservation planning. Several identified species are $\mathrm{DD}$, therefore range maps are far from accurate, and even uncertainties on their taxonomy and habitat requirements are often present (Appendix S1c). In principle, extinction risk might be inflated if the known distribution ranges underestimate the true distribution (Wallacean shortfall; Ficetola et al., 2014b). Despite these uncertainties, we believe our estimate is conservative, as we only considered species for which models generally have good performance (forest species), and for which human activities have already heavily altered the habitats. Our approach cannot be a substitute of the work of IUCN assessors, as the correct evaluation of species extinction risk requires direct information on taxa and their environments. 
Nevertheless, we believe that this set of species requires special attention and particular efforts by assessors in the future and that our approach can complement the assessment process. Furthermore, our models may be refined if more detailed information on habitat requirements (Almeida-Gomes et al., 2014) or ongoing habitat loss (Hansen et al., 2013) become available.

The Convention on Biological Diversity identified several major targets to reduce biodiversity loss by 2020. Among them, target 5 aims to significantly reduce habitat degradation and fragmentation (CBD Secretariat, 2010). However, measures of habitat area, trends and degradation and their impacts on species are only available for a small subset of species. The deductive models developed here allow an explicit quantification of habitat availability at the global scale and may be for instance used to identify species or areas suffering the highest threat levels. Furthermore, combining models with remote-sensing data may provide a dynamic information on how ongoing land cover changes impact species, helping to keep up-to date our information on the extinction risk of species (Rondinini et al., 2014).

\section{ACKNOWLEDGEMENTS}

We thank J. Measey and two anonymous referees for constructive comments on a previous version of this manuscript. G. F. Ficetola was partially funded by a scholarship of Univ. Milano-Bicocca. M. Lazzaroni, A. Cerutti and A. Corti greatly helped with data collection.

\section{REFERENCES}

Almeida-Gomes, M., Lorini, M.L., Rocha, C.F.D. \& Vieira, M.V. (2014) Underestimation of extinction threat to stream-dwelling amphibians due to lack of consideration of narrow area of occupancy. Conservation Biology, 28, 616-619.

Angulo, A. (2008) Hylodes pipilans. IUCN red list of threatened species. Version 2013.2. IUCN. www.iucnredlist.org (accessed 11 April 2014).

Bain, R., Biju, S.D., Brown, R., Das, I., Diesmos, A., Dutta, S., Gower, D., Inger, R., Iskandar, D.T., Kaneko, Y., Lau, M.W.N., Meegaskumbura, M., Ohler, A., Papenfuss, T.J., Pethiyagoda, R., Stuart, B., Wilkinson, M. \& Xie, F. (2008) Amphibians of the Indomalayan Realm. Threatened amphibians of the world (ed. by S.N. Stuart, M. Hoffman, J.S. Chanson, N.A. Cox, R.J. Berridge, P. Ramani and B.E. Young), pp. 80. Lynx Editions, IUCN and Conservation International, Barcelona.

Beale, C.M., Lennon, J.J., Yearsley, J.M., Brewer, M.J. \& Elston, D.A. (2010) Regression analysis of spatial data. Ecology Letters, 13, 246-264.

Becker, C.G., Fonseca, C.R., Haddad, C.F.B., Batista, R.F. \& Prado, P.I. (2007) Habitat split and the global decline of amphibians. Science, 318, 1775-1777.

Beebee, T.J.C. \& Griffiths, R.A. (2005) The amphibian decline crisis: a watershed for conservation biology? Biological Conservation, 125, 271-285.
Beresford, A.E., Buchanan, G.M., Donald, P.F., Butchart, S.H.M., Fishpool, L.D.C. \& Rondinini, C. (2011) Poor overlap between the distribution of Protected Areas and globally threatened birds in Africa. Animal Conservation, 14, 99-107.

Bicheron, P., Defourny, P., Brockmann, C., Schouten, L., Vancutsem, C., Huc, M., Bontemps, S., Leroy, M., Achard, F., Herold, M., Ranera, F. \& Arino, O. (2008) GLOBCOVER. Products description and validation report. Medias France, European Space Agency, Toulouse.

Blaustein, A.R. \& Kiesecker, J.M. (2002) Complexity in conservation: lessons from the global decline of amphibian populations. Ecology Letters, 5, 597-608.

Breheney, P. \& Burchett, W. (2013) visreg: visualization of regression models. $R$ package version 2.0-2. Available at: http:// CRAN.R-project.org/package $=$ visreg $($ accessed 11 December 2014).

CBD Secretariat. (2010) The strategic plan for biodiversity 2011-2020 and the aichi biodiversity targets. Document $\mathrm{UNEP} / \mathrm{CBD} / \mathrm{COP} / \mathrm{DEC} / \mathrm{X} / 2$. Secretariat of the Convention on Biological Diversity, Nagoya, Japan.

Chanson, J.S., Hoffman, M., Cox, N. \& Stuart, S.N. (2008). The state of the world's amphibians. Threatened amphibians of the world (ed. by S.N. Stuart, M. Hoffman, J.S. Chanson, N.A. Cox, R.J. Berridge, P. Ramani and B.E. Young), pp. 33-44. Lynx Editions, IUCN and Conservation International, Barcelona.

Clements, G.R., Bradshaw, C.J.A., Brook, B.W. \& Laurance, W.F. (2011) The SAFE index: using a threshold population target to measure relative species threat. Frontiers in Ecology and the Environment, 9, 521-525.

Cooper, N., Bielby, J., Thomas, G.H. \& Purvis, A. (2008) Macroecology and extinction risk correlates of frogs. Global Ecology and Biogeography, 17, 211-221.

Corsi, F., de Leeuw, J. \& Skidmore, A. (1999). Modeling species distribution with GIS. Research techniques in animal ecology (ed. by L. Boitani and T.K. Fuller), pp. 442. Columbia University Press, New York.

Curado, N., Hartel, T. \& Arntzen, J.W. (2011) Amphibian pond loss as a function of landscape change - A case study over three decades in an agricultural area of northern France. Biological Conservation, 144, 1610-1618.

Di Gregorio, A. \& Jansen, L.J.M. (2000) Land cover classification system: classification concepts and user manual. Food and Agriculture Organization of the United Nations. http://www.fao.org/docrep/003/X0596E/X0596e00.htm.

Dormann, C.F., McPherson, J.M., Araújo, M.B., Bivand, R., Bolliger, J., Carl, G., Davies, R.G., Hirzel, A., Jetz, W., Kissling, W.D., Kühn, I., Ohlemüller, R., Peres-Neto, P.R., Reineking, B., Schröder, B., Schurr, F.M. \& Wilson, R. (2007) Methods to account for spatial autocorrelation in the analysis of species distributional data: a review. Ecography, 30, 609-628.

Ficetola, G.F., Pennati, R. \& Manenti, R. (2012) Do cave salamanders occur randomly in cavities? An analysis with Hydromantes strinatii. Amphibia-Reptilia, 33, 251-259. 
Ficetola, G.F., Cagnetta, M., Padoa-Schioppa, E., Quas, A., Razzetti, E., Sindaco, R. \& Bonardi, A. (2014a) Sampling bias inverts ecogeographical relationships in island reptiles. Global Ecology and Biogeography, 23, 1303-1313.

Ficetola, G.F., Rondinini, C., Bonardi, A., Katariya, V., Padoa-Schioppa, E. \& Angulo, A. (2014b) An evaluation of the robustness of global amphibian range maps. Journal of Biogeography, 41, 211-221.

da Fonseca, G.A.B., Balmford, A., Bibby, C., Boitani, L., Corsi, F., Brooks, T., Gascon, C., Olivieri, S., Mittermeier, R.A., Burgess, N., Dinerstein, E., Olson, D., Hannah, L., Lovett, J., Moyer, D., Rahbek, C., Stuart, S. \& Williams, P. (2000) It's time to work together and stop duplicating conservation efforts. Following Africa's lead in setting priorities. Nature, 405, 393-394.

Gaston, K.J. (1991) How large is a species geographic range? Oikos, 61, 434-438.

Gaston, K.J. \& Fuller, R.A. (2009) The sizes of species' geographic ranges. Journal of Applied Ecology, 46, 1-9.

GRASS Development Team. (2008) Geographic resources analysis support system (GRASS) software. Open Source Geospatial Foundation Project. Available at: http:/grass.osgeo.org (accessed 11 December 2014).

Halverson, M.A., Skelly, D.K., Kiesecker, J.M. \& Freidenburg, L.K. (2003) Forest mediated light regime linked to amphibian distribution and performance. Oecologia, 134, 360-364.

Hansen, M.C., Potapov, P.V., Moore, R., Hancher, M., Turubanova, S.A., Tyukavina, A., Thau, D., Stehman, S.V., Goetz, S.J., Loveland, T.R., Kommareddy, A., Egorov, A., Chini, L., Justice, C.O. \& Townshend, J.R.G. (2013) Highresolution global maps of 21 st-century forest cover change. Science, 342, 850-853.

Hoekstra, J.M., Boucher, T.M., Ricketts, T.H. \& Roberts, C. (2005) Confronting a biome crisis: global disparities of habitat loss and protection. Ecology Letters, 8, 23-29.

Hof, C., Araujo, M.B., Jetz, W. \& Rahbek, C. (2012) Additive threats from pathogens, climate and land-use change for global amphibian diversity. Nature, 480, 516-519.

Hoffmann, M., Hilton-Taylor, C., Angulo, A. et al. (2010) The impact of conservation on the status of the world's vertebrates. Science, 330, 1503-1509.

Holt, B., Lessard, J.P., Borregaard, M.K., Fritz, S.A., Araujo, M.B., Dimitrov, D., Fabre, P.H., Graham, C.H., Graves, G.R., Jonsson, K.A., Nogues-Bravo, D., Wang, Z.H., Whittaker, R.J., Fjeldsa, J. \& Rahbek, C. (2013) An update of Wallace's zoogeographic regions of the world. Science, 339, 74-78.

Howard, S.D. \& Bickford, D.P. (2014) Amphibians over the edge: silent extinction risk of Data Deficient species. Diversity and Distributions, 20, 837-846.

IONIA. (2009) Globcover land cover. European Space Agency. http://due.esrin.esa.int/globcover/.

IUCN. (2001) IUCN red list categories and criteria: version 3.1. IUCN, Gland, Switzerland and Cambridge, UK.

IUCN. (2013) The IUCN red list of threatened species. Version 2013.1. Available at: http://www.iucnredlist.org (accessed 17 September 2013).
IUCN. (2014) The IUCN red list of threatened species. Version 2014.1. Available at: http://www.iucnredlist.org (accessed 21 June 2014).

Jenkins, C.N. \& Giri, C. (2008) Protection of mammal diversity in Central America. Conservation Biology, 22, 10371044.

Joly, P., Miaud, C., Lehmann, A. \& Grolet, O. (2001) Habitat matrix effects on pond occupancy in newts. Conservation Biology, 15, 239-248.

Kramer-Schadt, S., Niedballa, J., Pilgrim, J.D. et al. (2013) The importance of correcting for sampling bias in MaxEnt species distribution models. Diversity and Distributions, 19, 1366-1379.

Lahoz-Monfort, J.J., Guillera-Arroita, G. \& Wintle, B.A. (2014) Imperfect detection impacts the performance of species distribution models. Global Ecology and Biogeography, 23, 504-515.

Lips, K.R., Mendelson, J.R. III, Munoz-Alonso, A., CansecoMarquez, L. \& Mulcahy, D.G. (2004) Amphibian population declines in montane southern Mexico: resurveyes of historical localities. Biological Conservation, 119, 555-564.

Maindonald, J. \& Braun, W.J. (2010) Data analysis and graphics using $R$. Cambridge University Press, Cambridge.

Maiorano, L., Amori, G., Capula, M., Falcucci, A., Masi, M., Montemaggiori, A., Pottier, J., Psomas, A., Rondinini, C., Russo, D., Zimmermann, N.E., Boitani, L. \& Guisan, A. (2013) Threats from climate change to terrestrial vertebrate hotspots in Europe. PLoS ONE, 8, e74989.

Mendenhall, C.D., Sekercioglu, C.H., Brenes, F.O., Ehrlich, P.R. \& Daily, G.C. (2011) Predictive model for sustaining biodiversity in tropical countryside. Proceedings of the National Academy of Sciences USA, 108, 16313-16316.

Menéndez-Guerrero, P.A. \& Graham, C.H. (2013) Evaluating multiple causes of amphibian declines of Ecuador using geographical quantitative analyses. Ecography, 36, 756-769.

Olson, D.M., Dinerstein, E., Wikramanayake, E.D., Burgess, N.D., Powell, G.V.N., Underwood, E.C., D’Amico, J.A., Itoua, I., Strand, H.E., Morrison, J.C., Loucks, C.J., Allnutt, T.F., Ricketts, T.H., Kura, Y., Lamoreux, J.F., Wettengel, W.W., Hedao, P. \& Kassem, K.R. (2001) Terrestrial ecoregions of the worlds: a new map of life on Earth. BioScience, 51, 933-938.

Pope, S.E., Fahrig, L. \& Merriam, N.G. (2000) Landscape complementation and metapopulation effects on leopard frog populations. Ecology, 81, 2498-2508.

R Development Core Team. (2013) R: a language and environment for statistical computing. R Foundation for Statistical Computing, Vienna.

Rondinini, C., Wilson, K.A., Boitani, L., Grantham, H. \& Possingham, H.P. (2006) Tradeoffs of different types of species occurrence data for use in systematic conservation planning. Ecology Letters, 9, 1136-1145.

Rondinini, C., Di Marco, M., Chiozza, F., Santulli, G., Baisero, D., Visconti, P., Hoffman, M., Schipper, J., Stuart, S.N., Tognelli, M.F., Amori, G., Falcucci, A., Maiorano, L. \& 
Boitani, L. (2011a) Global habitat suitability models of terrestrial mammals. Philosophical Transactions of the Royal Society B: Biological Sciences, 366, 2633-2641.

Rondinini, C., Rodrigues, A.S.L. \& Boitani, L. (2011b) The key elements of a comprehensive global mammal conservation strategy. Introduction. Philosophical Transactions of the Royal Society B-Biological Sciences, 366, 2591-2597.

Rondinini, C., Di Marco, M., Visconti, P., Butchart, S.H.M. \& Boitani, L. (2014) Update or outdate: long-term viability of the IUCN Red List. Conservation Letters, 7, 126-130.

Skelly, D.K., Werner, E.E. \& Cortwright, S.A. (1999) Longterm distributional dynamics of a Michigan amphibian assemblage. Ecology, 80, 2326-2337.

Stuart, S.N., Chanson, J.S., Cox, N.A., Young, B.E., Rodriguez, A.S.L., Fischman, D.L. \& Waller, R.M. (2004) Status and trends of amphibian declines and extinctions worldwide. Science, 306, 1783-1786.

Stuart, S.N., Hoffman, M., Chanson, J.S., Cox, N.A., Berridge, R.J., Ramani, P. \& Young, B.E. (2008) Threatened amphibians of the world. Lynx Editions, IUCN and Conservation International, Barcelona, Spain.

United States Geological Survey. (2006) Shuttle radar topography mission 3 arc second version 2.0. Global Land Cover Facility, University of Maryland, College Park, MD. http:// www.landcover.org/data/srtm/.

Wright, S.J. \& Muller-Landau, H.C. (2006) The future of tropical forest species. Biotropica, 38, 287-301.

\section{SUPPORTING INFORMATION}

Additional Supporting Information may be found in the online version of this article:

Appendix S1. (a) List of species for which we developed suitability models; (b) list of species for which we did not develop models; (c) list of species for which extinction threat is likely underestimated.

\section{BIOSKETCH}

This work is the outcome of collaborative efforts between researchers of the Global Mammal Assessment Program and a group of specialists of amphibian conservation.

Gentile Francesco Ficetola is a researcher combining multiple approaches (landscape ecology, macroecology and evolutionary biology) to improve knowledge of the ecology and conservation of amphibians and reptiles.

Author contributions: G.F.F., E.P.-S. and C.R. designed the study; G.FF and C.R. gathered species data; G.F.F., A.B., D.B. and C.R. performed the analyses; G.F.F. wrote the first draft of the manuscript. All authors commented on and approved the final manuscript version.

Editor: David Richardson 